\title{
Indirect Fluorescence of Amines in Capillary Electrophoresis, Using Cresyl Violet
}

\author{
Ming-Feng Huang and Huan-Tsung Chang*
}

Department of Chemistry, National Taiwan University, Taipei, Taiwan, R.O.C.

\begin{abstract}
This paper describes the analysis of amines under acidic conditions by capillary electrophoresis (CE) in conjunction with indirect laser-induced fluorescence (ILIF), using cresyl violet as a probe. In the system, a small pinhole $(0.2 \mathrm{~mm})$ and an interference filter $(589 \mathrm{~nm})$ were used to confine the light and to minimize the plasma interference from a He-Ne laser, respectively, improving the baseline stability. Adding lithium ions to the background electrolytes (BGEs) is effective to achieve narrower peak profiles, leading to better resolution. The analysis of six amines by CE-ILIF using an aqueous solution, $\mathrm{pH} 3.5$, containing 5.0\% methanol, $0.1 \mathrm{mM}$ sulfuric acid, $0.1 \mathrm{mM}$ cresyl violet, and $0.3 \mathrm{mM}$ lithium was complete in $5 \mathrm{~min}$, with the limits of detection (LOD) on the level of $\mu \mathrm{M}$. Negative peak profiles are for amines with greater electrophoretic mobility than that of lithium ions, but positive peaks for the slower ones.
\end{abstract}

*Correspondence: Huan-Tsung Chang, Department of Chemistry, National Taiwan University, Roosevelt Road, Sec. 4, Taipei, 106 Taiwan, R.O.C.; E-mail: changht@ntu. edu.tw.

3387

DOI: $10.1081 /$ JLC-120025597

Copyright (C) 2003 by Marcel Dekker, Inc.
1082-6076 (Print); 1520-572X (Online) www.dekker.com 
To further improve the sensitivity, on-line concentration based on $\mathrm{pH}$ junction has been demonstrated. When injecting the sample prepared in a solution of $0.2 \mathrm{mM}$ sulfuric acid, $\mathrm{pH} 3.3$, at $15 \mathrm{kV}$ for $60 \mathrm{~s}$, and conducting the separation using the above-mentioned condition, the sensitivity improvements are greater than 10-fold compared to that injecting at $15 \mathrm{kV}$ for $5 \mathrm{~s}$. With the advantages of rapidity, sensitivity, and low cost, this method has proven potential for the analysis of trace amines in biological samples.

Key Words: Amines; Capillary electrophoresis; Cresyl violet; Laserinduced fluorescence; Indirect

\section{INTRODUCTION}

Indirect laser-induced fluorescence (ILIF), in conjunction with capillary electrophoresis (CE), has been tested and developed for analyzing a wide variety of solutes that have weak, or are lacking, optical properties such as fluorescence and absorption, including amines, metal ions, carboxylic acids, peptides, and carbohydrates. ${ }^{[1-5]}$ With the advantages of universality, sensitivity, speed, and efficiency, CE-ILIF is a powerful tool for the analysis of small volumes of complicated biological samples, such as the determination of alkaline metal ions and anions in single cells. ${ }^{[6,7]}$

Several factors affecting the sensitivity of CE-ILIF have been revealed and related theories have been proposed. ${ }^{[8,9]}$ According to Eq. (1), the dynamic reserve (DR) and transfer ratio (TR) for a system must be large in order to achieve a low detection limit (LOD). ${ }^{[10]}$

$$
C_{\mathrm{LOD}}=\frac{C_{\mathrm{m}}}{\mathrm{DR} \times \mathrm{TR}}
$$

Where $C_{\mathrm{LOD}}$ is the concentration limit of detection, and $C_{\mathrm{m}}$ is the concentration of relevant mobile-phase component, DR is the ability to measure a small change on top of a large signal, and is equal to a signal-to-noise ratio $(\mathrm{S} / \mathrm{N})$ of the background signal, and TR is the degree of displacement of the probe (coion) by the analyte. A large DR value is easily achieved by using a stable laser and dyes with high quantum yields. To obtain a large TR value, a fluorophore possessing a high charge density and a comparable mobility with analytes (in order to obtain symmetric peak profiles) is essential. ${ }^{[11]}$ In addition, the mobility of buffer-ions should be as different from that of analytes as possible to optimize TR. ${ }^{[12,13]}$

The analysis of amines is of importance and interest because of their roles in environmental and biological processes ${ }^{[14-18]}$ and has been conducted 
in CE-ILIF. ${ }^{[19]}$ For optimum sensitivity and resolution, in addition to the aboveaddressed parameters, $\mathrm{pH}$ is an important parameter on the analysis of amines by $\mathrm{CE}$-ILIF. Although a rapid analysis with a high resolving power can be achieved by conducting the separation at low $\mathrm{pH}$, loss of sensitivity due to the competitive displacement of probes by high concentrations of hydrogen ions in the background electrolyte (BGE) and by the analytes is problematic. On the other hand, loss of resolution and poor displacement of probes by amines are disadvantageous at high $\mathrm{pH}$. It has been demonstrated that the analysis of amines at $\mathrm{pH} 3.7$ is proper when using quinine as a probe. ${ }^{[20]}$ Unfortunately, a high-cost $\mathrm{Ar}^{+} \mathrm{UV}$ laser that needs expensive and routine maintenances was used in the system. In addition, loss of sensitivity due to high fluorescent background from the BGE and an unstable baseline sometimes occurs.

Our efforts to overcome these disadvantages have led to the search for fluorophores, with long maximum excitation wavelengths that can be excited by low-cost He-Ne lasers. Cresyl violet, with a maximum excitation wavelength at $592 \mathrm{~nm}$ and a maximum emission wavelength at $623 \mathrm{~nm}$, has been chosen for this purpose. Because it possesses amino groups as shown in Fig. 1, $\mathrm{pH}$ should play an important role in determining its fluorescence quantum yield and mobility. In this study, we investigated the effect of $\mathrm{pH}$ on resolution and sensitivity. We have also found that adding lithium ions to the BGE is effective to achieve narrower peak profiles and a more stable baseline.

\section{EXPERIMENTAL}

\section{Chemicals}

All chemicals were of reagent grade and were purchased from Sigma (St. Louis, MO). Aqueous BGEs were prepared from methanol, cresyl<smiles>N=c1cc2oc3cc(N)ccc3nc-2c2ccccc12</smiles>

Figure 1. Structure of the probe, cresyl violet, used in this study. 
violet, sulfuric acid, and lithium, as shown in the Results and Discussion section. The stock aqueous solution of $1 \mathrm{mM}$ cresyl violet was prepared in $50 \%(\mathrm{v} / \mathrm{v})$ methanol. All amine samples were prepared in aqueous solutions containing $0.3 \mathrm{mM}$ lithium and 0.1 or $0.2 \mathrm{mM}$ sulfuric acid. An aliquot of $0.1 \mathrm{~mL}$ beer from Taiwan Tobacco and Liquor Corporation was diluted with $0.9 \mathrm{~mL}$ aqueous solution containing $0.3 \mathrm{mM}$ lithium and $0.1 \mathrm{mM}$ sulfuric acid.

\section{Instrumentation}

The basic design of the NACE-ILIF system has been previously described. ${ }^{[21]}$ Briefly, a high-voltage power supply (Gamma High Voltage Research Inc., Ormond Beach, FL) was used to drive electrophoresis. The entire detection system was housed in a black box with a high-voltage interlock. The high-voltage end of the separation system was put in a laboratory-made plexiglass box for safety. A $5 \mathrm{~mW} \mathrm{He}-\mathrm{Ne}$ laser with an output at $594 \mathrm{~nm}$ from Melles Griot (Irvine, CA) was used for excitation. Between the laser output and the focusing lens, a pinhole with a diameter of $0.2 \mathrm{~mm}$ and a $589 \mathrm{~nm}$ interference filter (Edmund Industrial Optics, Barrington, NJ) was placed to reduce the spot size and to block the plasma from the laser, respectively. The emitted light was collected with a $10 \times$ objective (numeric aperture $=0.25$ ). One RG $610 \mathrm{~nm}$ cutoff filter was used to block scattered lights before the emitted light reached the photomultiplier tube (R928, Hamamatsu Photonics K. K., Shizuoka-Ken, Japan). The fluorescence signal was directly transferred through a $10-\mathrm{k} \Omega$ resistor to a 24-bit A/D interface at $10 \mathrm{~Hz}$ (Borwin, JMBS Developments, Le Fontanil, France), and stored in a personal computer. Fused-silica capillaries (Polymicro Technologies, Phoenix, AZ) used were $40 \mathrm{~cm}(30 \mathrm{~cm}$ in effective length $) \times 75 \mu \mathrm{m}$ I.D.

\section{Separation and Calculation}

Prior to use, new capillaries were equilibrated with suitable BGEs overnight. The sample injection was conducted at $15 \mathrm{kV}$ for either 5 or $60 \mathrm{~s}$, and the separation was carried out at $15 \mathrm{kV}$. Between runs, the capillaries were equilibrated with the BGEs for $10 \mathrm{~min}$. Resolution $\left(R_{\mathrm{S}}\right)$ was calculated according to $R_{\mathrm{s}}=2\left(t_{2}-t_{1}\right) /\left(t_{\mathrm{w} 1}+t_{\mathrm{w} 2}\right)$, where $t_{1}$ and $t_{2}$ are the migration times, and $t_{\mathrm{w} 1}$ and $t_{\mathrm{w} 2}$ are the peak widths at the baseline for components 1 and 2, respectively. LOD was calculated at a signal-to-noise ratio $(\mathrm{S} / \mathrm{N})$ of 3 . 


\section{RESULTS AND DISCUSSION}

\section{Effect of the Probe and Light Source}

When using cresyl violet as the probe, the analysis conducted at low $\mathrm{pH}$ should be efficient because it fluoresces more strongly than at high $\mathrm{pH}$, leading to a high DR. For example, the ratios of the fluorescence intensities for $0.1 \mathrm{mM}$ cresyl violet at $\mathrm{pH} 6.0,4.0$, and 3.0 to that at $\mathrm{pH} 8.0$, are $1.4,1.8$, and 2.0 , respectively. Low $\mathrm{pH}(<5.0)$ is also advantageous since cresyl violet is more soluble and stable (at least 4 weeks at $4{ }^{\circ} \mathrm{C}$ ). In addition to $\mathrm{pH}$, probe concentration is another important parameter. In terms of sensitivity, high probe concentrations are not suggested according to Eq. (1). On the other hand, probe concentrations lower than $50 \mu \mathrm{M}$ are not suitable, mainly because of low TR values due to a stronger competition of hydrogen ions to replace amines and lower DR values. To this end, the optimum concentration of cresyl violet in the BGEs is $50-100 \mu \mathrm{M}$ under acidic conditions.

In order to monitor a small change in a highly fluorescent background, achieving a stable baseline is of considerable importance. To reach this goal, the scattering light and plasma from the $\mathrm{He}-\mathrm{Ne}$ laser must be minimized. Cutting the spot size of the laser light down to about $0.2 \mathrm{~mm}$ by using a pinhole, makes it easier for focusing and is useful to minimize scattering light, which leads to improve the baseline stability. Adding an interference filter of $589 \mathrm{~nm}$, is effective to minimize the plasma interference and further improve the baseline stability. In consequence, without using a laser stabilizer, this simple and cost-effective setup allows one to achieve a DR value of 780 when using $0.1 \mathrm{mM}$ cresyl violet at $\mathrm{pH} 3.5$.

\section{Effect of Acids and Metal Ions}

Compared to phosphoric acid, sulfuric acid has been found more appropriate (higher DR) to adjust the $\mathrm{pH}$ of the BGEs. When using phosphoric acid, relatively high concentrations were required to adjust the BGE to a certain $\mathrm{pH}$ value, generating high Joule heats and obtaining low TR values. Although sulfuric acid was superior, the peak profiles were still very broad and dissymmetric, which caused losses of resolution, poor sensitivity, and irreproducibility. In order to circumstance these disadvantages, co-ions such as sodium, copper, and lithium, were separately added to the BGE. ${ }^{[1,13,22]}$ Adding sodium ions to the BGE, the peak profile only changed slightly, mainly because sodium ions $\left(\mu_{\mathrm{ep}}=4.91 \times 10^{-4} \mathrm{~cm}^{2} \mathrm{~V}^{-1} \mathrm{~s}^{-1}\right)$ migrated faster than most of the ammonium ions; copper ions caused peak broadening, presumably due to the formation of methylamine-copper complexes and greater differential electrophoretic 
mobilities between the ammonium and copper ions. The disadvantage was overcome by adding lithium ions to the BGE, mainly due to smaller differential electrophoretic mobilities between lithium $\left(\mu_{\mathrm{ep}}=3.86 \times 10^{-4} \mathrm{~cm}^{2} \mathrm{~V}^{-1} \mathrm{~s}^{-1}\right)$ and the ammonium ions (e.g., $\mu_{\mathrm{ep}}=3.61 \times 10^{-4} \mathrm{~cm}^{2} \mathrm{~V}^{-1} \mathrm{~s}^{-1}$ for diethylammonium ions). It is important to point out that the baseline also became more stable in the presence of lithium ions. Table 1 lists the effect of sulfuric acid and lithium on the peak height and bandwidth for methylamine. Although the peak profiles become narrower with increasing the concentration of lithium ions up to $2 \mathrm{mM}$, there is no clear trend in the changes in the peak height. This is because lithium ions deteriorated TR. In terms of efficiency (bandwidth) and sensitivity, the optimum condition was found when using a solution containing $0.1 \mathrm{mM}$ sulfuric acid and $0.3 \mathrm{mM}$ lithium ions.

\section{Separation of Amines}

Owing to very weak UV-VIS absorbance, the analysis of alkylamines by $\mathrm{CE}$ in conjunction with UV absorption detection is not practical. Using the

Table 1. Peak height and bandwidth for methylamine obtained under different conditions.

\begin{tabular}{lrc}
\hline & \multicolumn{2}{c}{ Methylamine } \\
\cline { 2 - 3 } $\mathrm{BGE}^{\mathrm{a}}$ & Peak height (V) & Bandwidth (min) \\
\hline $0.1 \mathrm{mM} \mathrm{H}_{2} \mathrm{SO}_{4} / \mathrm{Li}^{+}(\mathrm{mM})$ & 43,000 & 0.50 \\
0.1 & 40,000 & 0.30 \\
0.3 & 16,000 & 0.22 \\
0.6 & 12,000 & 0.12 \\
1.0 & & \\
$0.3 \mathrm{mM} \mathrm{H}_{2} \mathrm{SO}_{4} / \mathrm{Li}^{+}(\mathrm{mM})$ & 25,000 & 0.25 \\
0.3 & 30,000 & 0.20 \\
0.6 & 21,000 & 0.09 \\
1.0 & & \\
$1 \mathrm{mM} \mathrm{H} \mathrm{SO}_{4} / \mathrm{Li}^{+}(\mathrm{mM})$ & 24,000 & 0.16 \\
0.1 & 17,500 & 0.16 \\
0.5 & 5,200 & 0.11 \\
1.0 & 7,000 & 0.08 \\
2.0 & &
\end{tabular}

${ }^{\mathrm{a}}$ Separation conditions were as in Fig. 2 .

${ }^{\mathrm{b}}$ At the baseline. 
optimum conditions shown in Table 1, we tested the separation of six amines by CE-ILIF using cresyl violet. Figure 2 shows three negative peaks for methylamine, dimethylamine, and trimethylamine, as well as three positive peaks corresponding to diethylamine, benzylamine, and triethylamine, respectively. It is interesting to note that the negative peaks are for the amines with higher electrophoretic mobilities than that of lithium ions, indicating that cresyl violet ions were simply replaced by the cationic analytes. Compared to the first three negative peaks, the last three positive peaks that correspond to the amines with the electrophoretic mobility smaller than that of lithium ions are narrower and more symmetric. The positive peak profiles indicate that more cresyl violet ions were in the three analyte zones to balance the electricity. With more symmetric and narrower peak profiles, the sensitivity for the last three amines is greater than the first three. For example, the LOD at $\mathrm{S} / \mathrm{N}=3$ for trimethylamine and triethylamine were 1.3 and $0.9 \mu \mathrm{M}$, respectively. The sensitivity of this method is comparable to the reported values. ${ }^{[14,15]}$

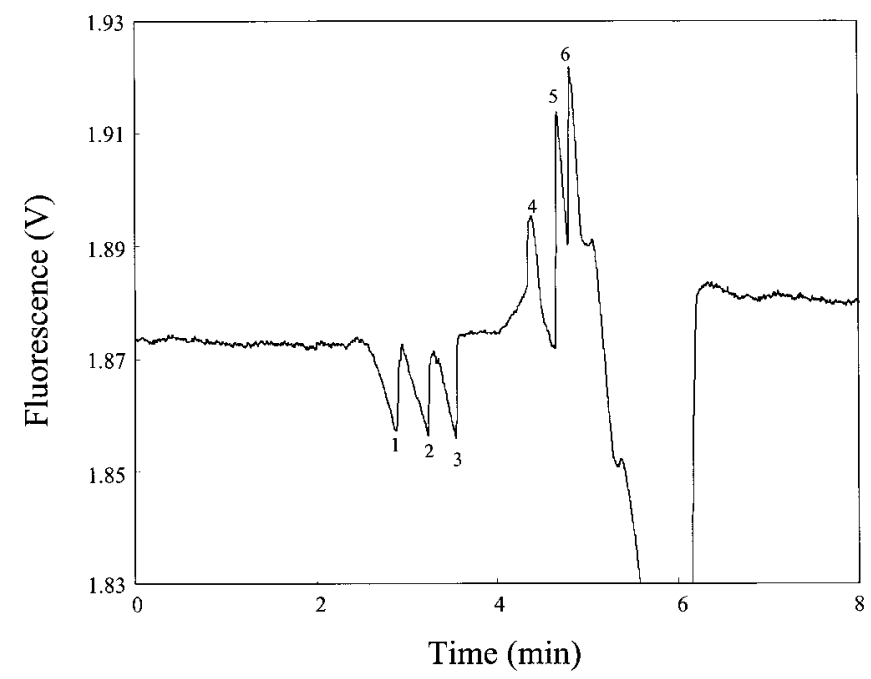

Figure 2. Electropherogram of the separation of six model amines at $15 \mathrm{kV}$ by CEILIF using cresyl violet. The amine sample was prepared in a solution at $\mathrm{pH} 3.5$ containing $0.1 \mathrm{mM}$ sulfuric acid and $0.3 \mathrm{mM}$ lithium. Capillary: $40 \mathrm{~cm}$ in total length and $30 \mathrm{~cm}$ in effective length; filled with a solution at $\mathrm{pH} 3.5$ containing $5.0 \%$ methanol, $0.1 \mathrm{mM}$ cresyl violet, $0.1 \mathrm{mM}$ sulfuric acid, and $0.3 \mathrm{mM}$ lithium ions. The injection was conducted at $15 \mathrm{kV}$ for $5 \mathrm{~s}$ and the amine concentrations were all $0.1 \mathrm{mM}$. Peak identity: 1 . methylamine; 2. dimethylamine; 3 . trimethylamine; 4. diethylamine; 5. benzylamine; and 6 . triethylamine. 
To test the feature of this method, the analysis of a diluted beer sample was conducted and the result is presented in Fig. 3. To identify some of the peaks shown in the electropherogram, the standards were spiked to the sample. Peaks 1-4 correspond to methylamine, diethylamine, benzylamine, and triethylamine, respectively. The migration times for these four analytes are slightly different from those shown in Fig. 2, mainly due to matrix effects. Our reasoning is supported by the fact that there is poor resolution and irreproducibility when injecting the beer sample without conducting dilution with the BGE. To determine the amine concentrations, standard addition was carried out, with results of $0.210 \pm 0.01,0.120 \pm 0.009$, and $0.060 \pm 0.006 \mathrm{mM}$ for diethylamine, benzylamine, and triethylamine, respectively. The other peaks in the electropherogram should correspond to different cationic solutes because the EOF (from the first system peak) is quite small $\left(1.2 \times 10^{-4} \mathrm{~cm}^{2} \mathrm{~V}^{-1} \mathrm{~s}^{-1}\right)$ at $\mathrm{pH} 3.5$. Compared to the electropherogram shown in Fig. 2, we suggest that a broad negative peak, around $3 \mathrm{~min}$, should correspond to a number of cations such as metal ions (e.g., sodium, calcium and magnesium) and other amines (e.g., dimethylamine and trimethylamine) that possess greater mobility than that of lithium ion. ${ }^{[14-19,23,24]}$ Several positive peaks marked as stars should correspond to amines that possess slower migration mobility than that of lithium ion, ${ }^{[14-19,23,24]}$ including tyramine and histamine that have been identified by standard addition.

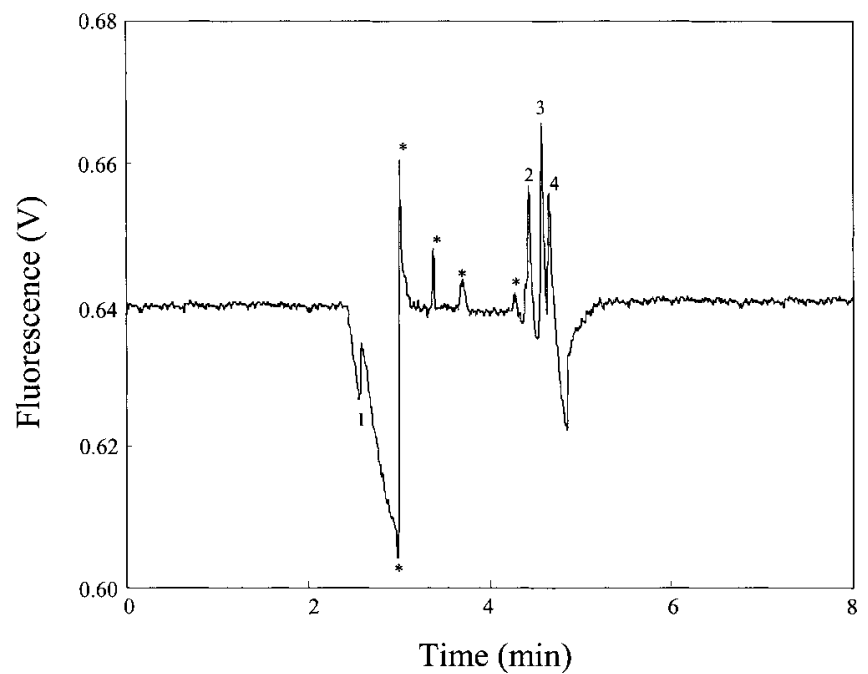

Figure 3. Separation of a beer sample diluted with the BGE by a factor of 10 . Peak identity: 1 . methylamine; 2 . diethylamine; 3 . benzylamine; and 4. triethylamine. Other conditions were as in Fig. 2. The peaks denoted by stars are reproducible but unidentified. 


\section{Stacking}

Several on-line concentration techniques in CE have been tested and developed for improving the sensitivity with varying degrees of success. ${ }^{\text {[25-32] }}$ For injecting large volumes of amines, the sample should be prepared in a medium at low conductivity and low $\mathrm{pH}^{[26,32]}$ Because the concentration of lithium ions at $0.3 \mathrm{mM}$ is essential in terms of sensitivity and resolution, changing the concentration of sulfuric acid was tested. The result listed in Table 2 clearly shows that the use of solutions containing high $(>1 \mathrm{mM})$ or low $(<10 \mu \mathrm{M})$ concentrations of sulfuric acid to prepare the amines was not appropriate for large-volume analysis. In the case of using high concentrations of sulfuric acid, the interference of hydrogen ion (loss of TR) is problematic. A small degree of protonation of benzylamine at high $\mathrm{pH}(0.28$ at $\mathrm{pH} 4.6)$ is the main reason for the loss of sensitivity using the BGE containing less than $10 \mu \mathrm{M}$ sulfuric acid. A poor stacking efficiency is another disadvantageous, which results from peak broadening because benzylamine accelerated when migrating from the sample zone $(\mathrm{pH} 4.6)$ to the BGE ( $\mathrm{pH} 3.5)$. In terms of sensitivity, the optimum concentration of sulfuric acid was $0.2 \mathrm{mM}$.

When the sample was prepared in a solution at lower $\mathrm{pH}$ (e.g., 3.3), amines slowed down at the boundary between the sample zone and the BGE ( $\mathrm{pH}$ 3.5). As a consequence, amines stacked when migrating from the sample zone to the BGE. The peak heights increased with increasing injection times ranging from 5 to $60 \mathrm{~s}$ when injecting at $15 \mathrm{kV}$. Figure 4 shows the electropherogram when injecting a sample consisting of six amines injected at $15 \mathrm{kV}$ for $60 \mathrm{~s}$, with a loss of resolution. The loss is mainly due to poor selectivity (shorter migration times) as the amines migrated faster at lower $\mathrm{pH}$. These shortages could not be overcome by simply increasing the conductivity and $\mathrm{pH}$ of the BGE or decreasing the $\mathrm{pH}$ of samples from the standpoint of ILIF. As a result, the injection volume is limited and stacking efficiency is poor. Based on the peak height for diethylamine, the LOD is $0.4 \mu \mathrm{M}$, which is about a 19-fold improvement in the sensitivity when compared to that obtained in the case of injecting at $15 \mathrm{kV}$ for $5 \mathrm{~s}$. Although the sensitivity improvement is not great, an impressive result was shown in the LOD of $0.07 \mu \mathrm{M}$ for triethylamine.

\section{CONCLUSIONS}

The analysis of amines under acidic conditions by CE-ILIF using cresyl violet and an orange $\mathrm{He}-\mathrm{Ne}$ laser $(594 \mathrm{~nm})$ is presented. We have found that lithium ions play an important role in determining the peak width, the baseline stability, and TR. To the best of our knowledge, this study presents the first successful result of stacking and separating six amines by CE-ILIF based on 6 


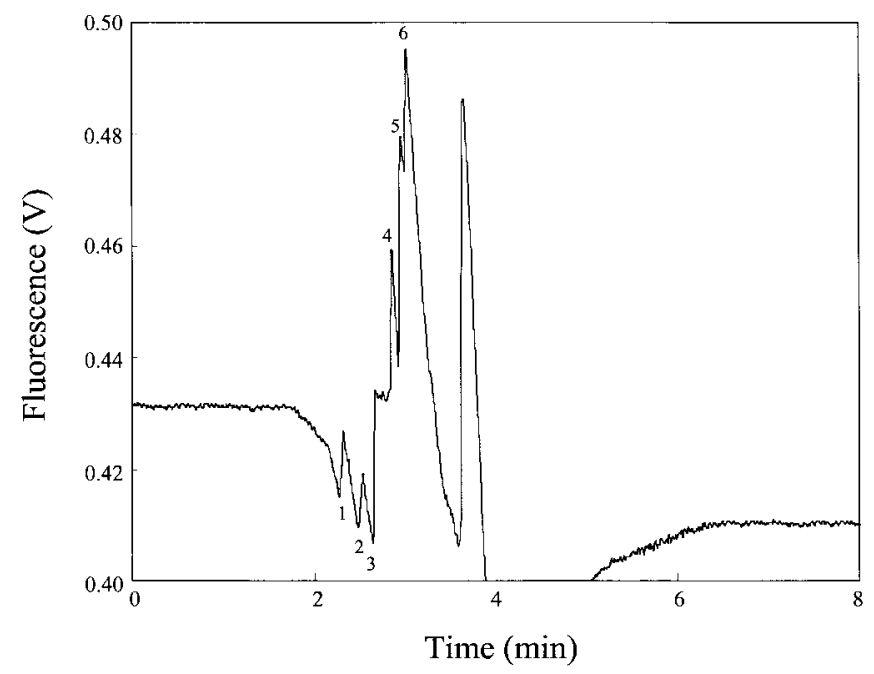

Figure 4. On-line concentration and separation of six amines at $15 \mathrm{kV}$ by CE-ILIF. The amines at the concentrations of $10 \mu \mathrm{M}$ were prepared in a buffer at $\mathrm{pH} 3.3$ containing $0.2 \mathrm{mM}$ sulfuric acid and $0.3 \mathrm{mM}$ lithium ions. The sample injection was conducted at $15 \mathrm{kV}$ for $60 \mathrm{~s}$. Other conditions were as in Fig. 2.

$\mathrm{pH}$ junction, with the LODs down to sub $\mu \mathrm{M}$ and the sensitivity improvements up to 19-fold. With the advantages of simplicity, sensitivity, rapidness, and low cost, this method has shown great potential for the analysis of amines and cations such as peptides and metal ions.

\section{ACKNOWLEDGMENT}

This work was supported by the National Science Council of the Republic of China (NSC 91-2113-M-002-052).

\section{REFERENCES}

1. Church, M.N.; Spear, J.D.; Russo, R.E.; Klunder, G.L.; Grant, P.M.; Andersen, B.D. Transient isotachophoretic-electrophoretic separations of lanthanides with indirect laser-induced fluorescence detection. Anal. Chem. 1998, 70, 2475-2480. 
2. Bread, N.P.; de Mello, A.J. A polydimethylsiloxane/glass capillary electrophoresis microchip for the analysis of biogenic amines using indirect fluorescence detection. Electrophoresis 2002, 23, 1722-1730.

3. Desbene, A.M.; Morin, C.J.; Mofaddel, N.L.; Groult, R.S. Utilization of fluorescein sodium salt in laser-induced indirect fluorimetric detection II. Application to organic anions. J. Chromatogr. A 1995, 716, 279-290.

4. Wallenborg, S.R.; Bailey, C.G. Separation and detection of explosives on a microchip using micellar electrokinetic chromatography and indirect laser-induced fluorescence. Anal. Chem. 2000, 72, 1872-1878.

5. Ruiz-Calero, V.; Puignou, L.; Galceran, M.T. Analysis of glycosaminoglycan monosaccharides by capillary electrophoresis using indirect laserinduced fluorescence detection. J. Chromatogr. A 2000, 873, 269-282.

6. Zhang, R.; Cooper, C.L.; Ma, Y. Determination of total polyamines in tumor cells by high-performance capillary zone electrophoresis (HPCZE) with indirect photometric detection. Anal. Chem. 1993, 65, 704-706.

7. Jin, L.J.; Wang, T.; Li, S.F.Y. Indirect laser-induced fluorescence detection of valproic acid in human serum by capillary electrophoresis. Electrophoresis 1999, 20, 1856-1861.

8. Shamsi, S.A.; Danielson, N.D.; Warner, I.M. Flavin mononucleotide for indirect laser-induced fluorescence detection of anions separated by capillary electrophoresis. J. Chromatogr. A 1999, 835, 159-168.

9. Lista, A.G.; Arce, L.; Ríos, A.; Valcárcel, M. Use of eosin as a fluorophore in capillary electrophoresis with laser detection. J. Chromatogr. A 2001, 919, 407-415.

10. Yeung, E.S.; Kuhr, W.G. Indirect detection methods for capillary separations. Anal. Chem. 1991, 63, 275A-282A.

11. Boček, P.; Gebauer, P.; Beckers, J.L. Success and failure with phthalate buffers in capillary zone electrophoresis. Electrophoresis 2001, 22, 11061111.

12. Nielen, M.W.F. Quantitative aspects of indirect UV detection in capillary zone electrophoresis. J. Chromatogr. 1991, 588, 321-326.

13. Beckers, J.L. Peak deformation in cationic analysis caused by system zones. Electrophoresis 2001, 22, 2684-2690.

14. Wu, J.; Wong, M.K.; Lee, H.K. Capillary zone electrophoretic determination of heterocyclic aromatic amine in rain. J. Chromatographic Sci. 1995, $33,712-716$.

15. Nagasawa, N.; Yashiki, M.; Iwasaki, Y.; Hara, K.; Kojima, T. Rapid analysis of amphetamines in blood using head space-solid phase microextraction and selected ion monitoring. Forensic Sci. Int. 1996, 78, 95-102.

16. Arce, L.; Ríos, A.; Valcárcel, M. Direct determination of biogenic amines in wine by integrating continuous flow clean-up and capillary 
electrophoresis with indirect UV detection. J. Chromatogr. A 1998, 803, 249-260.

17. Driouich, R.; Takayanagi, T.; Oshima, M.; Motomizu, S. Separation and determination of $n$-alkylamines and histamine by capillary zone electrophoresis using salicylaldehyde-5-sulfonate as a derivatizing reagent. J. Chromatogr. A 2001, 934, 95-103.

18. Lange, J.; Thomas, K.; Wittmann, C. Comparison of a capillary electrophoresis method with high-performance liquid chromatography for the determination of biogenic amines in various food samples. J. Chromatogr. B 2002, 779, 229-239.

19. Lada, M.W.; Kennedy, R.T. Quantitative in vivo monitoring of primary amines in rat caudate nucleus using microdialysis coupled by a flow-gated interface to capillary electrophoresis with laser-induced fluorescence detection. Anal. Chem. 1996, 68, 2790-2797.

20. Gross, L.; Yeung, E.S. Indirect fluorometric detection of cations in capillary zone electrophoresis. Anal. Chem. 1990, 62, 427-431.

21. Chiu, T.-C.; Huang, M.-F.; Huang, C.-C.; Hsieh, M.-M.; Chang, H.-T. Indirect fluorescence of aliphatic carboxylic acids in nonaqueous capillary electrophoresis using merocyanine 540. Electrophoresis 2002, 23, 449-455.

22. Gebauer, P.; Pantuckkova, P.; Boček, P. Analytical expediency of acidic and alkaline background electrolytes in capillary zone electrophoresis: role of system zones in single-co-ion systems. Anal. Chem. 1999, 71, 3374-3381.

23. Fu, S.; Li, D.; Lucy, C.A. Prediction of electrophoretic mobilities. Part 2: Effect of acid dissociation constant on the intrinsic mobilities of aliphatic carboxylates and amines. Analyst 1998, 123, 1487-1492.

24. Klampfl, C.W.; Himmelsbach, M.; Buchberger, W.; Klein, H. Determination of purines and pyrimidines in beer samples by capillary zone electrophoresis. Anal. Chim. Acta 2002, 454, 185-191.

25. Hsieh, M.-M.; Tseng, W.-L.; Chang, H.-T. On-column preconcentration and separation of DNA fragments using polymer solutions in the presence of electroosmotic flow. Electrophoresis 2000, 21, 2904-2910.

26. Britz-Mckibbin, P.; Chen, D.D.Y. Selective focusing of catecholamines and weakly acidic compounds by capillary electrophoresis using a dynamic pH junction. Anal. Chem. 2000, 72, 1242-1252.

27. Palmer, J.; Burgi, D.S. Munro, N.J.; Landers, J.P. Electrokinetic injection for stacking neutral analytes in capillary and microchip electrophoresis. Anal. Chem. 2001, 73, 725-731.

28. Zhu, L.; Lee, H.K. Field-amplified sample injection combined with water removal by electroosmotic flow pump in acidic buffer for analysis of phenoxy acid herbicides by capillary electrophoresis. Anal. Chem. 2001, 73, 3065-3072. 
29. Shihabi, Z.K. Stacking by electroinjection with discontinuous buffers in capillary zone electrophoresis. Electrophoresis 2002, 23, 2394-2398.

30. Britz-Mckibbin, P.; Otsuka, K.; Terabe, S. On-line focusing of flavin derivatives using dynamic $\mathrm{pH}$ junction-sweeping capillary electrophoresis with laser-induced fluorescence detection. Anal. Chem. 2002, 74, 37363743.

31. Urbánek, M.; Křivánková, L.; Boček, P. Stacking phenomena in electromigration: From basic principles to practical procedures. Electrophoresis 2003, 24, 466-485.

32. Chien, R.-L. Sample stacking revisited: A personal perspective. Electrophoresis 2003, 24, 486-497.

Received April 1, 2003

Accepted June 26, 2003

Manuscript 6118 
Copyright of Journal of Liquid Chromatography \& Related Technologies is the property of Marcel Dekker Inc. and its content may not be copied or emailed to multiple sites or posted to a listserv without the copyright holder's express written permission. However, users may print, download, or email articles for individual use. 